\title{
Aspectos morfoestruturais e morfotectônicos na evolução do relevo da bacia do Rio Paraibuna (MG) ${ }^{1}$
}

\author{
Morphostructural and morphotectonic aspects in the evolution \\ of the relief of the Paraibuna River basin (MG)
}

\author{
Felipe Pacheco Silva ${ }^{2}$ \\ Juliana Alves Moreira ${ }^{3}$ \\ Roberto Marques Neto ${ }^{4}$
}

DOI: https://doi.org/10.34019/2179-3700.2019.v19.29881

\begin{abstract}
Resumo
Os estudos concernentes à neotectônica intraplaca têm interpretado o papel dos esforços deformacionais recentes na evolução do relevo e da drenagem, conforme tem ocorrido em bordas cratônicas como os cinturões móveis reativados durante a separação da Placa Afrobrasileira e ao longo do Cenozoico. No sudeste brasileiro, o período neotectônico, estabelecido a partir da primeira fase deformacional das estruturas vinculadas ao rifte sudeste, tem forjado reorganizações nos sistemas geomorfológicos e engendrado o surgimento de redes de drenagem referenciadas nos níveis de base pregressamente estabelecidos, como o rio Paraíba do Sul e o próprio Oceano Atlântico. A bacia do rio Paraibuna partilha de um conjunto de bacias hidrográficas geradas nessas primeiras fases de reativação firmadas entre o Oligoceno e o Mioceno, apresentando heranças das estruturas preteritamente formadas e evidências de tectônica ativa, cuja conjugação foi estabelecida mediante uma compartimentação morfoestrutural e morfotectônica, que, comparadas, confirmaram a atuação esperada de diferentes controles e desvelaram especificidades acerca da tectônica ativa vigente na região.
\end{abstract}

Palavras-chave: Neotectônica. Índices geomorfométricos. Controle estrutural. Bacia do rio Paraibuna.

\begin{abstract}
The studies concerning to the intraplate neotectonic has being interpreting the recent deformational efforts role in the evolution of the relief and draining as it has being occurring in cratonic borders as the retrative mobile belts during the separation of the Afro Brazilian Plate and during de Cenozoic. In southeast Brazil the neotectonic period established from the first deformational fase of the structures linked to the southeastern rift has being forging reorganizations in the geomorphological systems and engendrating the emergence of draining nets referenced on the previously established base levels like Paraíba do Sul river and the Atlantic Ocean itself. The Paraibuna river basin shares a group of hydrographic basins generated in those

\footnotetext{
${ }^{1}$ Trabalho premiado no Seminário de Iniciação Científica da UFJF em 2016.

2 Bolsista de Iniciação Científica PIBIC/CNPq.

${ }^{3}$ Bolsista de Iniciação Científica BIC/UFJF.

${ }^{4}$ Professor do Departamento de Geociências e do Programa de Pós-graduação em Geografia da UFJF. End. Campus da Universidade Federal de Juiz de Fora - Rua José Lourenço Kelmer, S/Nº - São Pedro, Juiz de Fora - MG, 36036-900, Instituto de Ciências Humanas - Sala B-III-08. E-mail: roberto.marques@ufjf.edu.br
} 
first fases of reactivation formed between the Oligocene and the Miocene presenting heritages of the previously formed structures and evidences of active tectonic whose conjugation was established through a morphostructural and morphotectonic compartmentalization which in comparison confirmed the expected acting of different controls and unveiled specificities about the active tectonic present in the region.

Keywords: Neotectonic. Geomorphic indexes. Structural control. Paraibuna river basin.

\section{INTRODUÇÃO}

Este ensaio consiste na compilação dos resultados de projeto de pesquisa voltado para a investigação da evolução do relevo da bacia hidrográfica do Rio Paraibuna, sudeste de Minas Gerais, pelo prisma da neotectônica, cujos resultados foram divulgados parcialmente (SILVA et al. 2016; MOREIRA et al. 2016) em outras comunicações científicas.

De antemão, considera-se importante elucidar o que se compreende por feições morfoestruturais e feições morfotectônicas. As primeiras se associam a um controle "passivo", no qual as principais características do relevo denotam controle exercido pelo arcabouço litoestrutural, dado pela litologia presente e delimitada por certa configuração tectônica, sendo as formas elaboradas predominantemente por agentes erosivos (SAADI, 1991). As feições morfotectônicas, por seu turno, remetem ao componente "ativo" do relevo e englobam uma ligação efetiva entre a disposição dos elementos geométricos do substrato e da superfície do terreno com deformações crustais recentes, compreendidas como neotectônicas (ETCHEBEHERE, 2004).

A União Internacional para Estudos do Quaternário (INQUA)compreende que neotectônica refere-se a qualquer movimento da crosta ou deformação do nível de referência geodésico, seus mecanismos, sua origem, independentemente de sua idade de início, suas implicações práticas e suas extrapolações futuras, não possuindo um vínculo cronológico, devendo ser incluído toda a escala de tempo dos movimentos desde os instantâneos até $10^{7}$ anos, caso seja necessário para compreensão da gênese do movimento (BIGARRELLA et al. 2003).

Definido o escopo, a presente pesquisa intenciona discutir aspectos evolutivos no contexto do sistema geomorfológico da bacia hidrográfica do Rio Paraibuna a partir da interpretação do arranjo morfoestrutural conjuntamente às intromissões morfotectônicas sobrepostas às estruturas passivas. Destina-se, portanto, compreender a conexão da emolduração cenozoica do relevo a partir de processos não somente denudacionais, mas tectônicos, conforme tem sido levado a efeito por diversos autores no contexto do Brasil 
Sudeste (ASMUS e FERRARI, 1978; RICCOMINI, 1989; RICCOMINI et al., 1989; SAADI, 1991, SAADI, 1993; GONTIJO, 1999; SILVA; MELLO, 2011; MARQUES NETO, 2012; MOURA et al. 2013; REZENDE, 2013; MARENT, 2016).

\section{METODOLOGIA}

A primeira pauta metodológica da presente pesquisa consistiu na compilação das publicações e referências que tratam do tema estudado, priorizando os materiais versados no sudeste brasileiro. Concomitantemente, foi organizado um banco de dados na escala de 1/50.000, que congregou as cartas topográficas (em formato vetorial e matricial) do Instituto Brasileiro de Geografia e Estatística (IBGE), os litotipos e estruturas geológicas mapeadas no âmbito do Serviço Geológico do Brasil (CPRM), ortofoto Landsat 8 e Modelo Digital de Elevação da missão Shuttle Radar Topography Mission (SRTM) e do United States Geological Survey (USGS). A bacia do Rio Paraibuna, suas sub-bacias, canal principal e seus afluentes foram delimitados em formato vetorial, a partir dos dados do IBGE.

Os aspectos tectônicos foram analisados por meio dos lineamentos de relevo e drenagem decalcados sobre relevo sombreado com ângulo azimutal de $315^{\circ}$. A direção dos lineamentos foi identificada com uso da ferramenta Geometria Zonal como Tabela,presente no ArcGis 10.3.1. De posse desses dados foi gerado o diagrama de roseta fazendo uso do software GEOrient@).

Os parâmetros morfométricos mensurados foram os seguintes: Relação Declividade x Extensão do Canal - RDE (HACK, 1973; ETCHEBEHERE, 2004); Superfície de Base - SB (JAIN, 1984); Fator de Assimetria de Bacias - FABD (HARE; GARDNER, 1985); Fator de Simetria Topográfica Transversal - FSTT (COX, 1994) e; Sinuosidade da Escarpa Montanhosa - Smf (BULL e WALLACE, 1985).

\section{RESULTADOS E DISCUSSÃO}

Os compartimentos geomorfológicos (Figura 1) apresentados para área de estudo por Marques Neto et al. (2017) revelam uma configuração morfológica diversa, sendo possível reconhecer padrões distintos para os diferentes setores da bacia, bem como as variações entre o alto, médio e baixo curso. Constata-se que os setores alto e baixo da bacia apresentam um controle mais expressivo, congregando alinhamentos de cristas e morros de topos aguçados em conjunto com drenagens que entalham vales encaixados e 
com desvios abruptos recorrentes. De modo contrastante, o relevo do médio curso e de expressiva porção da margem esquerda evidencia um padrão tipicamente mamelonizado com uma diversa e irregular rede hidrográfica de padrão dominantemente dendrítico a subdendrítico. Entretanto, até mesmo nestas porções, onde a vaga erosiva apresenta um maior êxito, componentes da imposição litoestrutural se revelam evidentes nas estruturas NE-SW posicionadas na passagem do médio para o baixo curso, nos arredores do núcleo urbano de Juiz de Fora. Este quadro geomorfológico figurou como a base espacial do relevo para as interpretações morfoestruturais e morfotectônicas na bacia.

Figura 1 - Compartimentos geomorfológicos
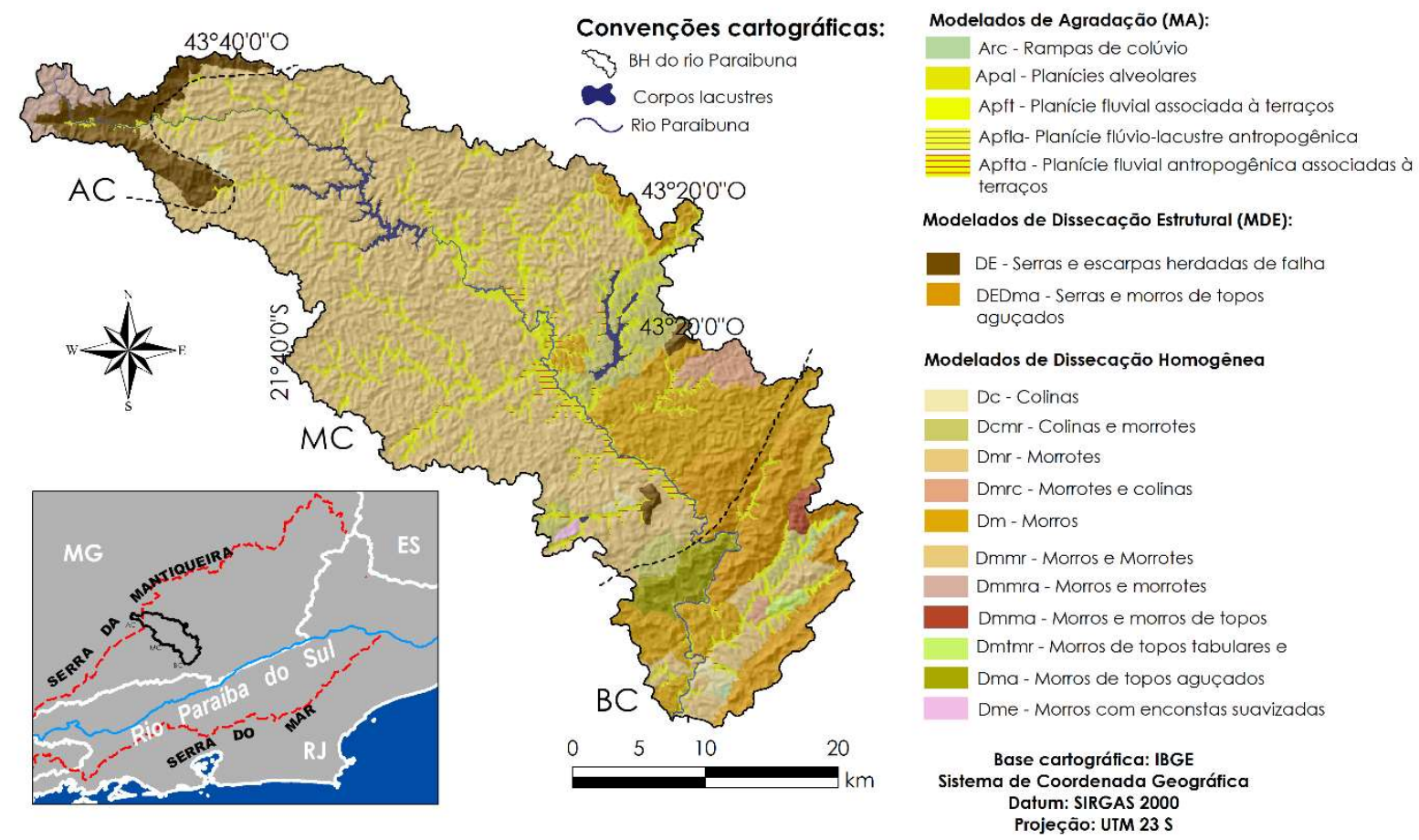

Fonte: adaptado de Marques Neto et al. (2017).

Moreira et al. (2016), dialogando sobre os resultados de FABD e FSTT, apresentam como os índices morfométricos são complementares e antagônicos em alguns aspectos. A análise conjunta potencializa a interpretação das assimetrias e seu significado tectônico. Com base nas exposições de Moreira et al. (2016) é possível apontar que: a) a bacia do Rio Paraibuna apresenta um basculamento da margem direita, expresso também pelo predomínio de altas e médias assimetrias nas sub-bacias da margem direita; b) as sub-bacias com maior assimetria de FABD, também reúnem maiores assimetrias de FSTT, até mesmo sub-bacias simétricas apresentam valores elevados de FSTT; c) as 
assimetrias das sub-bacias distribuem-se sob diferentes litologias distintas, contudo, apresentando configurações dos canais atrelados a componentes NE-SW e NW-SE. A reunião dos mapas de FABD, SB e RDE é apresentada na Figura 2.

Silva et al. (2016) apontam que a interpretação do mapa de SB permite diferenciar quatro contextos definidos a partir dos seguintes intervalos: a) de 1200 a 1000 metros identifica-se a maior concentração das curvas ajuntadas, sendo essa porção correspondente ao contexto serrano do alto curso, estando em coerência com os maiores valores encontrados de RDE; b) de 1000 a 700 metros tem-se um arranjo de isobases espaçadas, ligadas em grande parte ao contexto de dissecação homogênea em morros e morrotes; c) de 700 a 600 metros tem-se novamente uma maior concentração das curvas de superfície de bases, se notando nesta área um maior ímpeto da tectônica ressurgente, a exemplo da reorientação do rio principal para NE-SW atendendo à reativação de falhas preexistentes; d) de 600 a 450 metros instaura-se novamente uma organização de curvas de isobases espaçadas, sendo relativas a um relevo mais dissecado com predomínio de morrotes e colinas.

De acordo com Silva et al. (2016), os valores de RDE variam na bacia do rio Paraibuna em função de contatos litológicos e de componentes morfotectônicos. Os RDEs totais apresentaram variação entre 22 e 90 . Ao averiguar o perfil longitudinal do rio Paraibuna conjuntamente às anomalias, cumpre destacar que dois setores do rio apresentaram valores mais agudos $(67,6$ e 121,8), sendo essas as duas maiores anomalias de primeira ordem identificadas na área de estudo, visto que em apenas 30 metros de comprimento o canal entalha 40 metros. Nesse trecho o rio Paraibuna vence uma soleira, à montante da qual se desenvolve a maior parte de área urbana, primordialmente edificada nas planícies e terraços que se desenvolvem acima da ruptura de declive, feição que foi reconhecida por Ab'Sáber (2007) na sua tese de doutoramento.

Nesse sentido, se constata que os resultados de FABD, SB e RDE apresentam uma nítida correlação das anomalias e assimetrias a determinados setores da bacia, e que reportam as implicações neotectônicas. Ademais, ficam evidentes íntimas relações entre os modelados de dissecação em controle estrutural com setores de alta energia e encaixamento do canal, a exemplo do que ocorre na passagem para o baixo curso, quando o rio Paraibuna passa a dissecar um bloco em soerguimento. Os limites do gráben, no qual o referido canal fluvial se aloja em grande parte do seu percurso superficial, também são bem marcados por anomalias na configuração das isolinhas e por 
respostas nos valores de RDE. O controle tectônico é verificado em praticamente todos os contextos morfológicos da bacia, com destaque para a zona que marca a passagem do médio para o baixo curso, onde a planície fluvial é estrangulada e o canal passa a entalhar verticalmente com agressividade.

Figura 2 - Mapas de Fator de Assimetria da Bacia de Drenagem, Superfície de Base, Relação Declividade x Extensão do Canal e Perfil longitudinal do Rio Paraibuna, com destaque para as anomalias de drenagem à jusante de Juiz de Fora. 


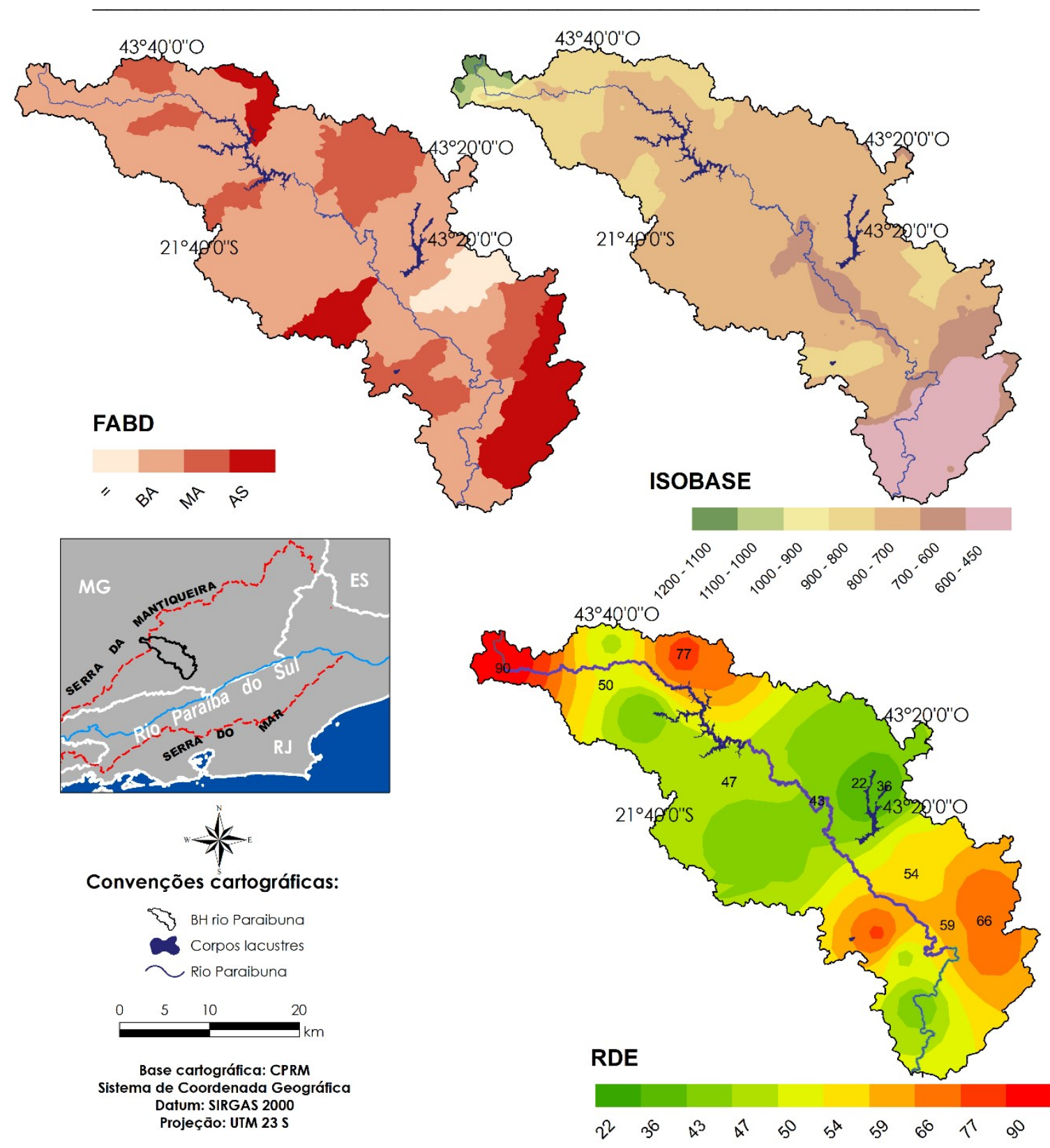

PERFIL LONGITUDINAL DO RIO PARAIBUNA:

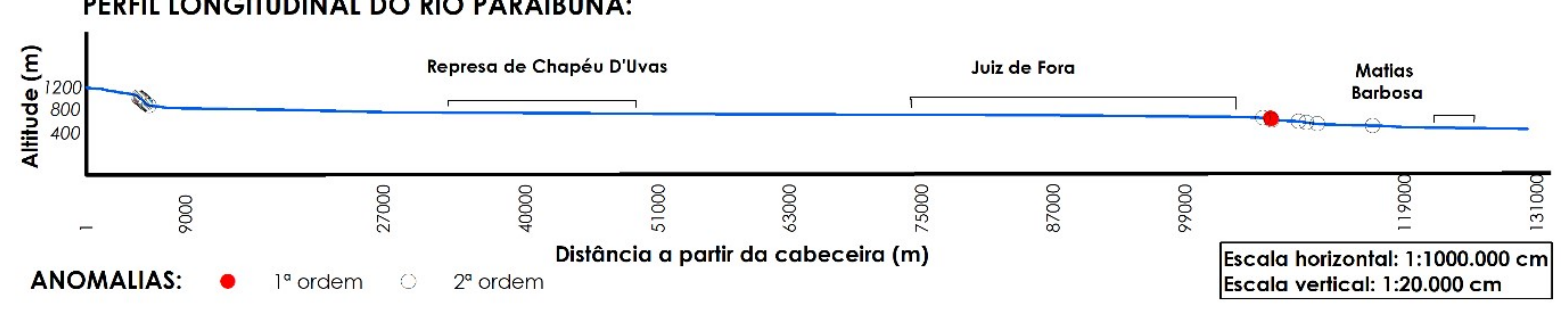

Fonte: adaptado de Silva et al. (2016) e Moreira et al. (2016).

Em complemento, o Índice Sinuosidade da Escarpa Montanhosa - Smf (Quadro 1), acusou um maior controle tectônico atuando nas cristas posicionadas no baixo curso em detrimento daquelas que balizam as linhas interfluviais do alto curso, mais reafeiçoadas 
pela erosão remontante. As feições alinhadas que exercem controle no baixo curso, vinculadas ao bloco em ascensão, apresentaram valor mais baixo de Smf, apresentando tendência na manutenção das feições retilíneas.

Quadro 1 - Sinuosidade da Escarpa Montanhosa com destaque para Serra do Mina que apresenta uma maior retilineidade

\begin{tabular}{lcccc|}
\hline Denominação do alinhamento & Lmf & Ls & Smf \\
\hline Serra da Mantiqueira (NE) & 23290,5 & 13733,87 & 1,695843925 \\
\hline Serra da Mantiqueira (SE) & 28318,1 & 17499,43 & 1,618229851 \\
\hline Serra do Mina (SW) & 7185,41 & 4938,33 & 1,455028319 \\
\hline
\end{tabular}

Fonte: adaptado de Moreira et al. (2016).

No que concerne aos lineamentos, a rosácea de direção demonstra o predomínio do componente E-W (Figura 3), reforçando a interpretação do tectonismo ativo bem marcado em falhas transcorrentes, correlata ao regime de esforços neotectônicos identificados para a plataforma brasileira, conforme o Word Stress Map (WSM), apresentado por Heildbach e Höhne (2008). Nesse aspecto, também são expressivos alinhamentos NE-SW interceptados por estruturas NW-SE e E-W que se distribuem por toda bacia, porém concentrando-se no baixo curso (jusante de Juiz de Fora), interpretado por Silva et al. (2016) como um bloco ascensional, constatado pela incisão expressiva do canal que engendra um vale confinado associado fundo raso mesmo mediante entalhe agressivo, e pela quase ausência de estocagem sedimentar; os afloramentos conspícuos favorecem o represamento de sedimentos de barras de canal e a formação de efêmeras ilhas fluviais.

O embasamento litológico diversificado no qual se estabelecem as principais direções dos lineamentos indicam tênue controle da estruturação pretérita sobre estes, relevando a subordinação do componente estrutural aos arranjos impostos pela tectônica ativa no rejuvenescimento das estruturas pretéritas do trend principal NE-SW da Faixa Ribeira (SILVA et al., 2009), mas, sobretudo, relacionada a ampliação do componente EW, ligado a falhas transcorrentes, conforme sublinhado por Silva et al. (2016) e Moreira et al. (2016).

Figura 3 - Mapa geológico com lineamentos de relevo e drenagem, com diagrama de 
roseta, sendo possível evidenciar o predomínio da orientação E-W

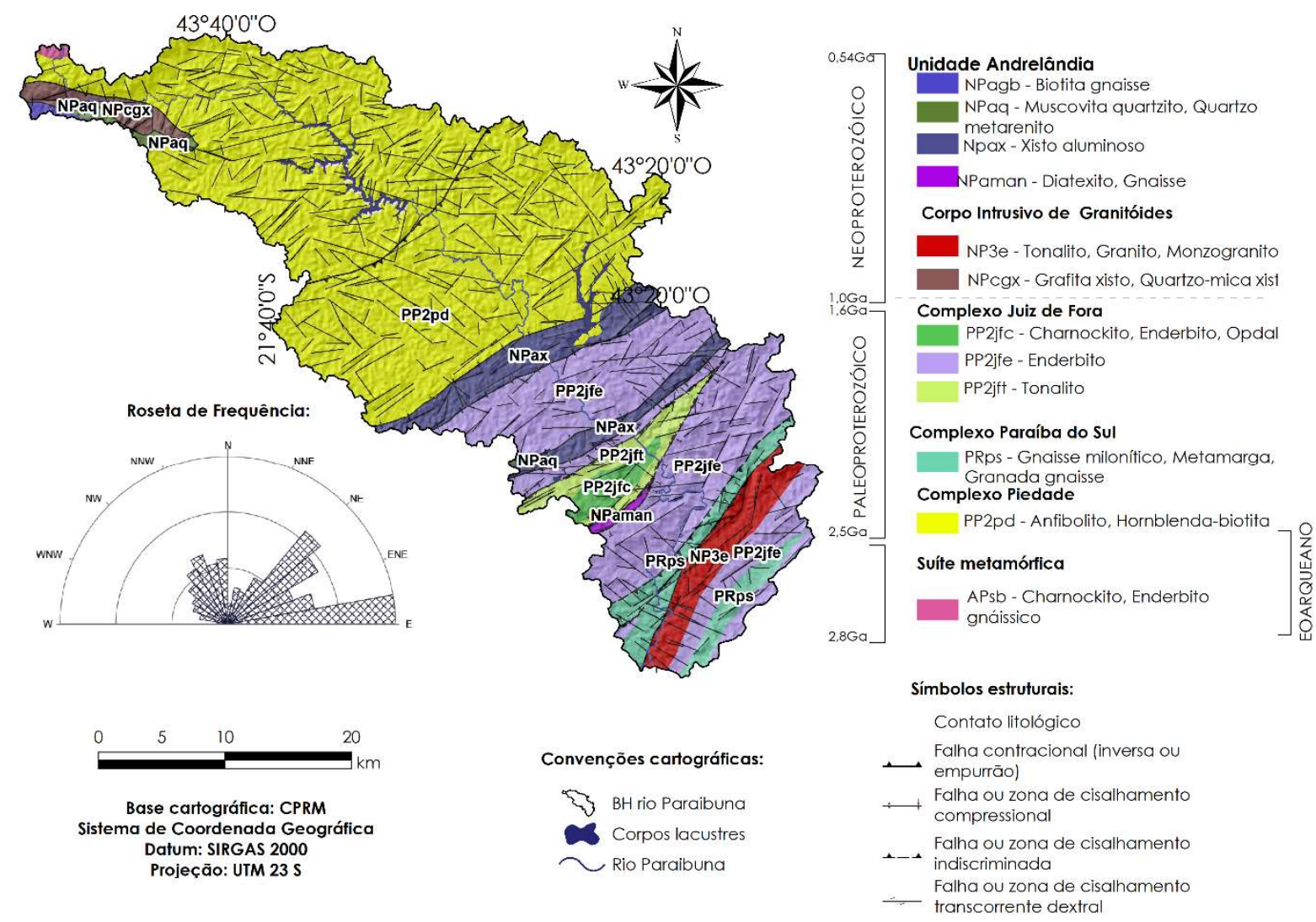

Fonte: adaptado de Silva et al. (2016).

\section{CONSIDERAÇÕES FINAIS}

Comparando os aspectos morfoestruturais e morfotectônicos, é possível afiançar o papel do componente neotectônico no rejuvenescimento da paisagem, corroborado pelos dados geomorfométricos e litoestruturais, bem como pelas evidências geomorfológicas. Isto se confirma, principalmente, pela forte correlação dos setores anômalos entre si a partir dos diferentes índices. Dessa forma, cabe destacar que os resultados obtidos reportam claramente a um quadro de tectônica recente na área, evidenciando reativações de falhas preexistentes.

A bacia hidrográfica do rio Paraibuna apresenta considerável agressividade erosiva e consequente obliteração das morfologias estruturalmente controladas, tal como ocorre em outros sistemas hidrográficos diretamente conectados ao nível de base geral. Compreende-se, portanto, que a drenagem avulta como atributo do meio físico de grande relevância na interpretação de elementos neotectônicos atuantes na evolução do relevo, permitindo identificar comportamentos fora do padrão e ampliar os indícios de evidências de cunho morfotectônico. Na área de estudo, tais evidências encontram-se sobrepostas 
às estruturas preexistentes, forjando um controle híbrido que opera em um sistema geomorfológico de notável complexidade tectono-erosiva.

\section{AGRADECIMENTOS}

Os autores agradem ao Conselho Nacional de Desenvolvimento Científico e Tecnológico (CNPq) e a Pró-Reitoria de Pós-Graduação e Pesquisa (PROPP) da Universidade Federal de Juiz de Fora (UFJF) pelas bolsas de pesquisas concedidas que permitiram a realização desta pesquisa.

\section{REFERÊNCIAS}

AB'SÁBER, A. N. Geomorfologia do sítio urbano de São Paulo. São Paulo: Ateliê Editorial, 2007.

ASMUS, H. E.; FERRARI, A. L. Hipótese sobre a causa do tectonismo cenozoico na região sudeste do Brasil. Série Projeto REMAC, Rio de Janeiro, v.4 p. 75-88, 1978.

BIGARELLA, J. J.; PASSOS, E.; HERMANN, M. L. P.; SANTOS, G. F.; MENDONÇA, M.; SALAMUNI, E.; SUGUIO, K. Estrutura e origem das paisagens tropicais de subtropicais. v. 3. Florianópolis: Ed. UFSC, 2003.

BULL, W. B., WALLACE, R. E. Tectonic geomorphology. Geology, n. 13, 1985, p. 216. COX, R. T. Analysis of drainage-basin symmetry as a rapid technique to identify areas of possible Quaternary tilt-block tectonics: An example from the Mississippi Embayment.

Geological Society of America Bulletin, v. 106, n. 5, p. 571-581, 1994.

ETCHEBEHERE, M. L. C. Aplicação do índice "Relação Declividade-Extensão - RDE" na bacia do Rio do Peixe (SP) para detecção de deformações neotectônicas. Geologia USPSéries Científicas, São Paulo, v. 4, n. 2, p. 43-56, 2004.

GONTIJO, A. H. F. Morfotectônica do médio vale do Rio Paraíba do Sul: região da Serrada Bocaina, estados de São Paulo e Rio de Janeiro. 1999, 259 p. Tese (Doutorado em Geologia) - Instituto de Geociências e Ciências Exatas, Universidade Estadual Paulista, Rio Claro, 1999.

HACK, J.T. Stream-profile analysis and stream-gradient index. U.S. Geol. Survey. Jour. Research, v. 1, n. 4, p. 421-429, 1973.

HARE, P.W., GARDNER, T.W. Geomorphic indicators of vertical neotectonism along converging plate margins, Nicoya Peninsula, Costa Rica. In: MORISAWA, M., HACK, J.T. (ed.), Anais 15th Annual Bighamton Geomorphology Symposium. Nicoya Peninsula, Costa Rica,p. 75-104.

HEILDBACH, O; HÖHNE, J. CASMI. A visualization tool for the Word Stress Map database. Computers e Geosciences, Karlsuhe, v. 34, p. 783-791, 2008. 
JAIN, V.E. Geotectónica general. Moscou: Mir Ed., 1984.

MARENT, B.R.; Geomorfogênese dos Degraus escalonados do Sudeste de Minas Gerais. 2016. 190 f. Tese (Doutorado em Geografia) - Instituto de Geociências, Universidade Federal de Minas Gerais, Belo Horizonte, 2016.

MARQUES NETO, R. Estudo evolutivo do sistema morfoclimático e morfotectônico da bacia do Rio Verde (MG), sudeste do Brasil. 2012, 429p. Tese (Doutorado em Geografia) - Instituto de Geociências e Ciências Exatas, Universidade Estadual Paulista, Rio Claro, 2012.

MARQUES NETO, R.; SILVA, F. P.; FERNANDES, R. A.; BARRETO, J. C.; EDUARDO, C.C. A espacialidade do relevo em paisagens transformadas e sua representação: mapeamento geomorfológico da bacia do Rio Paraibuna, Sudeste de Minas Gerais. Revista Ra'e Ga., Curitiba, v. 41 Temático de Geomorfologia, p. 65-81, 2017.

MOREIRA, J. A.; SILVA, F. P.; MARQUES NETO, R. Aplicação de índices geomórficos para interpretação do quadro morfoestrutural e morfotectônico da bacia do Rio Paraibuna (MG). In: SIMPÓSIO MINEIRO DE GEOGRAFIA, 2., 2016, Juiz de Fora. Anais [...]. Juiz de Fora: UFJF, 2016. p. 1059-1072.

MOURA, T. C; MARQUES NETO, R; OLIVEIRA, T. A; REIS, A. V. P. Aplicação do índice "Relação Declividade x Extensão do curso" (RDE) na bacia hidrográfica do rio Lourenço Velho (MG) como subsídio à detecção de deformações neotectônicas. Revista de GeografiaUFJF, Juiz de Fora, v. 3, n. 1, p. 1-8, 2013.

REZENDE, E. A. Evolução do relevo no divisor hidrográfico entre as bacias dos rios Grande e Paraíba do Sul: um estudo na Serra da Mantiqueira (MG/RJ).2013. 189 p. Tese (Doutorado em Geografia) - Instituto de Geociências, Universidade Federal de Minas Gerais, Belo Horizonte, 2013.

RICCOMINI, C. O rift continental do sudeste do Brasil. São Paulo, 1989. 256 p. Tese (Doutorado em Geologia) - Instituto de Geociências, Universidade de São Paulo, São Paulo, 1989.

RICCOMINI, C.; PELOGGIAA. U. G.; SALONI J. C. L.; KOHNKE M. W.; FIGUEIRA R. M. Neotectonic activity in the Serra do Mar rift system (southeastern Brazil). Journalof South American Earth Sciences, v. 2, n. 2, p. 191 -197, 1989.

SAADI, A. Ensaio sobre a morfotectônica de Minas Gerais: tensões intra-placa, descontinuidades crustais e morfogênese. 1991. 286 p. Tese (Professor Titular) - Instituto de Geociências, Universidade Federal de Minas Gerais, Belo Horizonte, 1991.

SILVA, C. M. T.; ALKMIN, F. F.; PEDROSA-SOARES, A. C. Geometria e evolução do feixe de zonas de cisalhamento Manhuaçu - Santa Margarida, Orógeno Araçuaí, MG. Revista Escola de Minas, v. 62, n. 1, p. 1-11, 2009.

SILVA, F.P.; MOREIRA, J.A.; MARQUES NETO, R.; BARRETO, J.C.B. O uso de dados 
geomorfométricos e estruturais como subsídio à interpretação do papel da neotectônica na evolução do relevo da bacia hidrográfica do Rio Paraibuna - MG. In:SIMPÓSIO NACIONAL DE GEOMORFOLOGIA, 11., 2016, Maringá. Anais eletrônicos [...]. Maringá: UEM, 2016. Disponível em:http://www.sinageo.org.br/2016/trabalhos/1/1-12-1503.html Acesso em: 12 nov. 2018.

SILVA, T. P.; MELLO, C. L. Reativações neotectônicas na Zona de Cisalhamento do Rio Paraíba do Sul (Sudeste do Brasil). Revista do Instituto de Geociências, v. 11, n. 1, p. 95-111, 2011. 